\title{
METHODOLOGICAL APPROACHES TO THE ACHIEVEMENT OF BALANCE AT ORGANIC PRODUCT MARKET
}

\author{
Ruschitskaya O. A. Zyryanova T. V. Kot E. M. Lavrov V. N. \\ Federal State Budget Educational Institution of Higher Education "Ural State Agrarian University" \\ (FSBEI HE Ural State University)
}

\begin{abstract}
The achievement of market economy balance state is a long-term problem and it has not been solved yet practically, as evidenced by the entire historical experience of the world economy. Although a significant number of scientific publications is known in this regard, related mainly with the development of balance theory and methodology at different territorial and sectoral levels. According to I. Schumpeter [11], the concept of "balance in the economy has to do with the uniqueness of its manifestation and can be viewed as an abstraction from the methodological aspect". Some economists-theoreticians defend the "multiplicity of balances", proceeding from the market model and the exchange at non-equilibrium prices $[6,10,7]$. That is, they consider basically the task of a balanced price achievement at the market. Many researchers reduce their theoretical positions to the level of economic models (the methods of evolutionary game experimental theory, the theory of complex systems, dynamic stochastic equilibrium models, etc.) $[1,5]$. The striving for price equilibrium at the market is limited by the peculiarity of its model, therefore, in our opinion, it is possible to develop the theoretical designs for an equilibrium state achievement by this criterion only in a short time interval.
\end{abstract}

Keywords: achievement of balance, organic, product market

\section{INTRODUCTION}

Since the price equilibrium can only be manifested in a competitive market model, which is probably not available yet in any industry, it should be viewed at the inter-branch level. This approach is also quite acceptable for the AIS, whose industry and organizations suffer losses from price inequivalence.

This applies to agriculture especially, whose interaction with other AIS spheres has not found a wide positive application yet. It loses its positions at the food market, and is forced to sale its products to a disadvantageous intermediary represented by a large commercial capital. In this bundle it is difficult to ensure a stable price equilibrium, especially in the system of "agricultural producer-intermediary-consumer".

Obviously, OPM market will function according to this scenario, on which the achievement of a rational supply-demand balance in conditions close to the equilibrium economy is regarded as important.

\section{STUDY RESULTS}

If we proceed from the canonical ideas about market equilibrium according to L. Valras and A. Marshall, the main components of its achievement are represented by volumes and price [8]:
$\mathrm{Q}_{\mathrm{d}}(\mathrm{P})=\mathrm{Q}_{\mathrm{s}}(\mathrm{P})$
$\mathrm{P}_{\mathrm{d}}(\mathrm{Q}) \leq \mathrm{P}_{\mathrm{s}}(\mathrm{Q})$,

Where $Q_{d}, Q_{s}$ is the volume of demand and supply, respectively, $P_{d}, P_{s}$ is the price of demand and supply, respectively.

In the first equation, the balance is established under the influence of an excessive volume of demand or supply on a price, which can be represented as a quantitative "adjustment" of the market mechanism (the relationship is shown on Figure 1). 


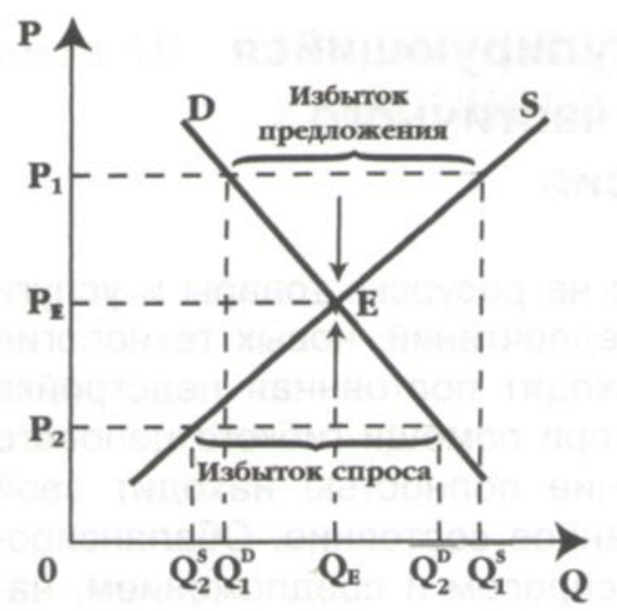

Figure 1 - The establishment of Valras equilibrium

In the second equation, equilibrium is established under the influence of supply and demand price difference, characteristic of the long-term period (Fig. 2)

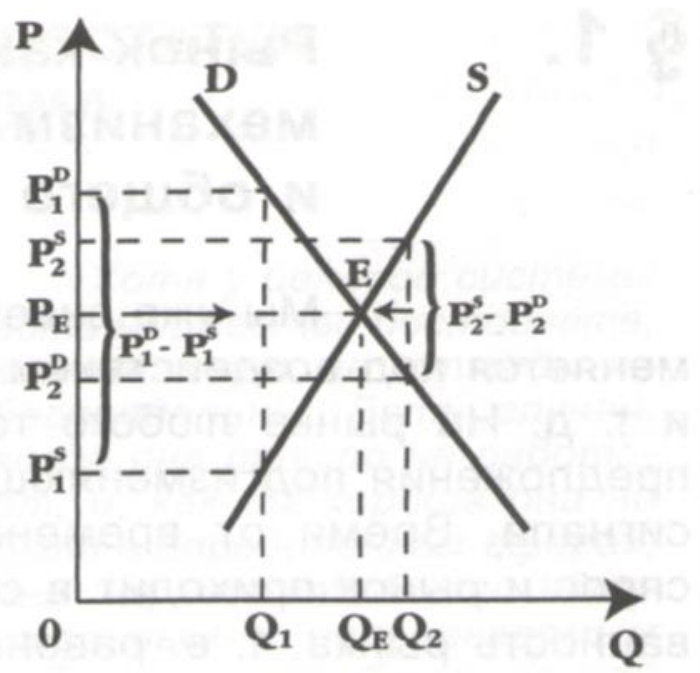

Figure 2 - Marshal balance establishment

These relationships operate mainly in a competitive production environment at the absence of transaction costs. If there is the competition of their producers at OPM food market, and the level of transaction costs is constant in a short-term period, then the market mechanism can be adjusted to self-regulation.

However, in practice, even in a short term, under the influence of various kinds of bifurcation manifestations, the process of self-regulation is violated at the market and the agrarian sector inevitably requires a state support and other institutional measures, that is, the measures that support market equilibrium. The solution of this problem is related with the scientific substantiation of an equilibrium state mechanism achievement at the food markets, as evidenced by various approaches set forth in the well-known publications.

For example, V. Lobanov [3] solves the problem of supply and demand balance achievement at the food market separately (using the example of dairy products), determining the quantitative characteristics of this product supply economic stability on the basis of optimal output value calculation. At the same time, the demand model for products is developed on the basis of the constant elasticity utility function mechanism and is represented by the system of the following three equations: 


$$
\left.\begin{array}{l}
p \frac{d f}{d z_{1}}-w_{1}-y \frac{d g}{d z_{1}}=0 \\
p \frac{d f}{d z_{2}}-w_{2}-y \frac{d g}{d z_{2}}=0 \\
b=g\left(z_{1}, z_{2}\right)
\end{array}\right\}
$$

where $w_{1}$ - the unit cost of fixed assets of the kind $z_{1}$;

$w_{2}$ - the cost of a workforce unit of the kind $z_{2}$;

$b$ - the shares of resources in production

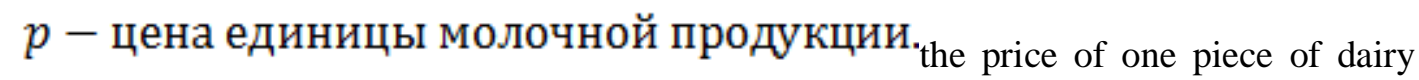
product

Rational behavior condition among the buyers of dairy products:

$$
\left.\begin{array}{l}
\sum_{i=1}^{n} \frac{a_{1}}{1-b_{i}}\left(x_{i}-\bar{x}_{i}\right)^{1-b_{i}} \rightarrow \max \\
\sum_{i=1}^{n} x_{i} p_{i} \leq I S \\
x_{1} \leq 0, \ldots x_{n} \geq 0
\end{array}\right\}
$$

That is, it is required to determine the value of each consumed type of dairy products $\mathrm{x}_{\mathrm{i}}, \mathrm{i}=\overline{1, n}$, so that the total cost of all these products $\sum_{i=1}^{n} p_{i} x_{i}$ does not exceed the size of IS budget, allocated for its acquisition, and the utility function takes the maximum value.

Then, the demand function for the i-th type of dairy products is determined, depending on the price of dairy products and the size of the family budget allocated for the purchase of dairy products.

$x_{i}=\overline{x_{i}}+\left[\frac{y p_{i}}{a_{i}}\right]^{\frac{1}{b_{i}}}$ or $x_{i}=x_{i}\left(p_{i_{x} \ldots . .} p_{n,} I S\right)$,

where $\overline{X_{2}}$ is the minimum amount of i-th type of dairy products, which can satisfy the minimum demand of customers;

$X_{i}$ is the required quantity;

$a_{i}$ is the coefficient expressing the buyer's preference for a particular type of dairy products. The higher the value $a_{i}$, the more preferable the given dairy product;

$b_{i}$ - the coefficient characterizing the proportion of the i-th dairy product in the total set of dairy products;

$\mathrm{y}$ - the amount of a family budget, thousand rubles.

$p_{i}$ - the price of dairy products, rubles / liter.

The mentioned mathematical apparatus for optimal forecasted volumes of production (supply) and consumption (demand) calculation at the food market of dairy products raises the following doubts:

- Firstly, the inclusion of two main indicators only in the supply function: product prices and production factors (fixed assets) does not give a complete picture of the forecasted level of supply optimality;

- Secondly, the stability of these prices is taken as a limitation, which is unlikely even in a short term;

- Thirdly, two indicators are used during the determination of demand function for a specific type of dairy products: the price of dairy products and the amount of family budget allocated for their purchase (by types), while the volume of demand entering the market in different periods of the calendar year is not taken into account. Therefore, the averaging of the indicators arises, which distorts the optimality of the obtained calculated results.

In this regard, it is useful to include a number of indicators in the limitations of supply function. For example, the indicators expressing the level of demand stability $(\mathrm{dc})$, and the level of supply stability $\left(\mathrm{S}_{\mathrm{n}}\right)$ in demand

Submit Date: 10.01.2018, Acceptance Date: 23.02.2018, DOI NO: 10.7456/1080MSE/130

Research Article - This article was checked by Turnitin

Copyright (C) The Turkish Online Journal of Design, Art and Communication 
function limitation, combining the presented system of equations. In the symbols of functional dependence, this supply can be represented as follows:

$$
\left.\begin{array}{l}
P R\left(Z_{1}, Z_{2}\right)=p f\left(Z_{i}\right)-\sum_{i=1}^{n} W_{i} Z_{i} \rightarrow \max \\
F P\left(x_{1} \ldots, x_{n}\right)=\sum_{i=1}^{n} \frac{a_{i}}{1-b_{i}}-\left(x_{i}-\bar{x}\right)^{1-b_{i}} \rightarrow \max
\end{array}\right\}
$$

At the limitations:

$\mathrm{a}>0,0<\mathrm{b}<1$

$\mathrm{Z} \geq 0$;

$\sum_{i=1}^{n} P_{i} X_{i} \leq \mathrm{G}$ - the cost of agricultural products should not exceed a family budget - $\mathrm{G}$ (or household budget in general);

$0<d_{i}^{c}=S_{i}^{n}<1-$ the condition of demand $\left(d_{i}^{c}\right)$ and supply $\left(S_{i}^{n}\right)$ stability level equality at the market of i-th agricultural product;

$\bar{X}=q_{\mathrm{H}}=q_{i}<G$ - the share of a family budget for food on the i-th product does not exceed its total income, without falling to the level of a scientifically based standard.

It should be noted that the use of functional dependencies, although it increases the scientific nature of the study, but does not take into account the fact that the correlation character of the interrelations between the performance indicator and the factor characteristics is most often manifested in economic processes.

This approach to stabilization problem solution at the food market was used by V. Klyukach and D. Melnikov [2]. Based on the MS Excel data analysis module for a particular type of agricultural products, a regression equation was developed: $\mathrm{Y}=\propto \mathrm{P}+\mathrm{bcX}+\mathrm{C}$, where $\mathrm{Y}$ is the volume of sales, $\mathrm{P}-$ the retail price of a product, $\mathrm{X}$ - the per capita income (rubles per person per month)..

However, the static nature of imposed restrictions on a price or a volume of sales invariability, as well as the fixed level of the product supply, do not allow us to consider the process of market balance achievement in dynamics.

In order to overcome static nature and achieve the equilibrium in market economy during a short run, $\mathrm{Kh}$. Gizatullin [4] offers to use the following formula:

$P(t)=P(0) \exp \left(\frac{d x_{c}}{d p} \cdot \frac{1}{E_{c}}-\frac{d x_{n}}{d p} \cdot \frac{1}{E_{n}}\right) \cdot t$,

where $\mathrm{P}(\mathrm{t})$ is the equilibrium price as a function of time $\mathrm{t}$;

$\mathrm{X}_{c}, \mathrm{X}_{\mathrm{n}}$ - the value of a product supply and demand, respectively;

$\mathrm{E}_{\mathrm{c}}, \mathrm{E}_{\mathrm{n}}$ - the elasticity of a product demand and supply, respectively;

$\mathrm{P}(0)$ - the product market price at the initial moment.

At that $E_{c}=\frac{d x_{c}}{d P} \cdot \frac{P}{x_{c}}, E_{n}=\frac{d x_{n}}{d P} \cdot \frac{P}{x_{n}}$

This formula can be used mainly at the macro level, although its simplicity is obvious, since it can be used only in limited circumstances (the presence of perfect competition at the market, the invariability of production opportunities and the economic interests of business partners). It is useful to relate this model to the population employment and income for more substantiated conclusions regarding the equilibrium state of supply and demand in the market, taking into account the property of "propensity to consume."

O. Fetyukhina [8], using production functions for the processed and unprocessed agricultural products, and relating the demand with the "character of society", as well as with the OPM import-export and consumption norms, attempted a mathematical justification to achieve an equilibrium state at OPM market. At the same time, the dynamics of production volume change in time (Пi) is represented by the following equation in Russia:

$\frac{d \Pi_{i}}{d t}=K_{i} \cdot\left[\propto N+\left(S_{i}-\Delta_{i}-b_{i}\right)\right] \Pi_{\mathrm{i}}$ 
where $\Pi_{\mathrm{i}}$ is the volume of the $\mathrm{i}$-th product export-import;

$K_{i}$ - the coefficient reflecting the dynamics of market equilibrium for the product $\Pi_{\mathrm{i}}$;

$S_{i}, \Delta_{i}$ - the coefficients expressing Russian market position in the world relative to the product $\Pi_{i}$;

$b_{i}$ - product supply outstripping ratio $\Pi_{\mathrm{i}}$;

$\propto$ - the coefficient expressing the society nature.

At the same time, the equation describing the dynamics of production volumes concerning the primary types of agricultural products, uses the coefficient reflecting the rates of leveling the difference in the supply-demand ratio. It means that this "procedure" will have to be carried out by state regulation, which considerably narrows the possibilities of the proposed differential equation application to equalize the supply-demand ratio at OPM market.

The timeliness of the difference "leveling" in supply and demand ratio is also questionable, especially since the methodology for coefficient calculation is not provided.

In order to solve this problem, a methodical approach is offered by the thesis author, the essence of which is stated in the following formula:

$$
\begin{aligned}
& \gamma=\frac{\sum_{i=1}^{n} E_{d i}}{\sum_{i=1}^{n} E_{s i}} \cdot j_{y} \cdot j_{\mathrm{pc}} \cdot j_{\mathrm{pm}}=\left[\sum_{i=1}^{n}\left(\frac{\Delta W_{i}^{\mathrm{mo}}}{W_{i}^{\mathrm{mo}}} \div \frac{\Delta P_{i}^{\mathrm{mo}}}{P_{i}^{\mathrm{mo}}}\right) / \sum_{i=1}^{n}\left(\frac{\Delta W_{i}^{\mathrm{p}}}{w_{i}^{\mathrm{p}}} \div \frac{\Delta P_{i}^{\mathrm{p}}}{P_{i}^{\mathrm{p}}}\right)\right] \cdot j_{y} \cdot j_{\mathrm{pc}} \cdot j_{\mathrm{pm}} \\
& =\left[\sum_{i=1}^{n}\left(\frac{\Delta W_{i}^{\mathrm{mo}}}{w_{i}^{\mathrm{mo}}} \div \frac{\Delta P_{i}^{\mathrm{mo}}}{P_{i}^{\mathrm{mo}}}\right) / \sum_{i=1}^{n}\left(\frac{\Delta W_{i}^{\mathrm{p}}}{w_{i}^{\mathrm{p}}} \div \frac{\Delta P_{i}^{\mathrm{p}}}{P_{i}^{\mathrm{p}}}\right)\right] \cdot K_{\mathrm{y}}^{\mathrm{mo}} / K_{\mathrm{y}}^{\mathrm{p}} \cdot K_{\mathrm{y}}^{\mathrm{po}} / K_{\mathrm{y}}^{\mathrm{c}} \cdot K_{\mathrm{y}}^{\mathrm{pn}} / K_{\mathrm{y}}^{\mathrm{mp}}, \text { (10) }
\end{aligned}
$$

where: $\gamma$-the coefficient, taking into account the level of supply and demand balance at the agro-product market;

$E_{d i}, E_{s i}$ - elasticity coefficients for the demand and the supply of the i-th type of agricultural products;

$j_{y}, j_{\mathrm{pc}}, j_{\mathrm{pm}}-$ the indices expressing, the ratio of supply and demand stability level, population fertility and mortality, food costs and the profits of agro-organizations;

$\Delta W_{i}^{\text {mo }}, \Delta W_{i}^{\mathrm{p}}$ - the volume of consumption (demand) and sale of the i-th type of agroproduct;

$K_{\mathrm{y}}^{\mathrm{mo}}, K_{\mathrm{y}}^{\mathrm{p}}, K_{\mathrm{y}}^{\mathrm{po}}, K_{\mathrm{y}}^{\mathrm{c}}, K_{\mathrm{y}}^{\mathrm{pm}}, K_{\mathrm{y}}^{\mathrm{mp}}$ - the coefficients of sustainability concerning consumption, supply, fertility, mortality, food costs and the profits of agro-organizations (for 1 year period).

Let's test this formula using the example of whole-milk products for the conditions of the Sverdlovsk region. To do this, we exclude the last two indices $\left(j_{\mathrm{pc}}, j_{\mathrm{pm}}\right)$ from the formula $(10)$, since they express all types of agroproducts. The calculations will be more objective for the products received, since whole milk is produced only in the region under consideration and is not included in the import, meeting the requirements of qualitative indicators. In order to calculate $\gamma$ we use statistical data from official sources. Substituting the actual values for the symbols of the formula, we get the following:

$\gamma_{\mathrm{M}}$

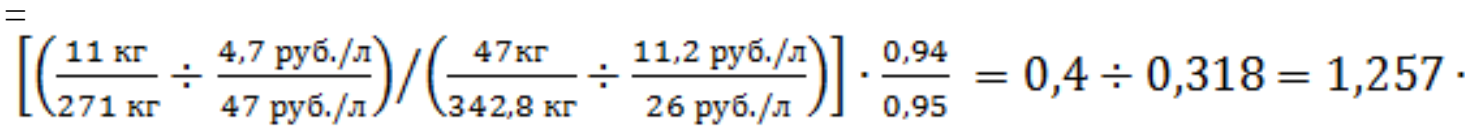

$$
\begin{aligned}
& 0,989=1,243
\end{aligned}
$$

Here:

$11 \mathrm{~kg}$ - an average annual increase of milk consumption per person;

$271 \mathrm{~kg}$ - an annual milk consumption, $\mathrm{kg} /$ person; 
4.7 rubles/l, 47 rubles/ - the increase of the average market price for whole milk products and its level in 2016, respectively;

$47 \mathrm{~kg}, 342.8 \mathrm{~kg}$ - the increase of milk sales for the period under review (5 years) and its annual volume, respectively;

11.2 rubles/l, 26 rubles/ - the increase of selling price among agricultural organizations and its value in 2016, respectively.

$0.94 ; 0,95$ - the coefficients of stability concerning the volume of milk consumption (demand) and production (supply), respectively.

\section{CONCLUSIONS}

1. By the value of the coefficient characterizing the level of supply and demand balance in the agro-products market by the ratio of their elasticity values, adjusted for the coefficients of their stability, we can conclude that the level of this market imbalance makes $24.3 \%$ (1.243 x 100\%).

2. By the coefficient of demand elasticity ((Ed), which is less than 1 , it can be judged that the demand for milk is inelastic one, and the supply is elastic (Es), as the price grows less than an offer change, that is, the offer is more responsive to demand change. This paradox arises from the difference between sale and market prices for milk.

3. An average retail price (from the farm) is 26 rubles/l, and the market price (because of trade mark-ups) reaches 47 rubles/liter (for comparison: in Tyumen - 60 rubles per liter). Therefore, agricultural farms are ready to increase an offer, even with a slight increase of the selling price.

\section{SUMMARY}

Hence the state must compensate the farms for the losses from the production of whole milk products. Referring to the value of the received coefficient $(=1,243)$ for the Sverdlovsk region, the level of compensation can be taken at the rate of $24.3 \%$. That is, the procurement prices for this product should be increased by this amount, which will bring it closer to equilibrium one.

This particularly applies to organic agricultural products, the demand for which depends not only on the price, but also on the guarantee of the required quality, the achievement of which is associated with the high risks of this product making.

Probably, Russia has no agricultural enterprises producing really organic agricultural products. If mineral fertilizers are not used somewhere, then tools are used to control locusts or nitrate organic fertilizers are introduced into the fields. Even if all the regulatory parameters are observed by a risky farmer, there is no guarantee of a necessary ecological level in respect of produced products, since the land does not correspond to the products grown on a particular field. Or there is a high weediness by unwanted weeds on the adjacent fields, etc.

Therefore, a consumer must realize the real price of organic produced products, which is expedient to include in the information support system of the population in each region of the country. Such a measure can increase an aggregate demand for "green" agricultural products and provide the basis for supply and demand regulation at its market.

\section{CONFLICT OF INTEREST}

The authors confirm that the presented data do not contain a conflict of interest.

\section{ACKNOWLEDGMENTS}

The work was prepared with the support of the FSBEI HE "Ural State Agrarian University" in Yekaterinburg. 


\section{REFERENCES}

A.A. Ashimov, B.T. Sultanov, Zh.M. Adilov, Yu.V. Borovsky, N.Yu. Borovsky, As. A. Ashimov "On the application of parametric regulation theory for computable general equilibrium models. Economics and mathematical methods, 2010, Vol. 46, No. 3, pp. 109-116.

Klyukach V.A. Organizational and economic mechanism of food supply for megalopolis: theory, methodology, practice // V.Klyukach, D. I. Melnikov - M.,. / Rosselkhozakademiya Publishing House, 2004. - 309 p. (pp. 207215).

Lobanov V.S. Regulation of dairy product markets: based on the materials of the Chelyabinsk region: the author's abstract from the thesis aimed to the scientific degree of the candidate of economic sciences. Chelyabinsk: ChAIA, 2012.

Mustaev I.Z. The use of accumulated potentials for development model design /I.Z. Mustaev, Kh.N. Gizatullin // Journal of Economic theory. - 2015. - No. 3. - pp. 122-134.

Polbin A.V. Drobyshevsky S.M. The development of a dynamic stochastic general equilibrium model for Russian economy. Moscow, Publishing House of Gaidar Institute, 2014 -156 p.

Svetlov M.M. The methodology of agricultural food policy modeling in the context of Eurasian integration. The bulletin of Timiryazevskaya Agricultural Academy № 3. Publisher: Russian State Agrarian University - MSAA named after. K.A. Timiryazev (Moscow). 2016, pp. 94-114.

Svetlov M.M. Alternative equilibria at agrarian markets // Journal of Economic Theory. 2016 - №3 - pp. 188202.

Fetyukhina O.N. The functioning and the development of the agricultural-food market of Russia in the conditions of globalization: theory, methodology, practice: dissertation aimed to the degree of Doctor of Economic Sciences. Stavropol, 2011.

Chepurin M.N. The course of economic theory [Text]: Textbook for universities / ed. by M.N.Chepurina, E.A. Kiseleva. - 7th ed., revised and added. - Kirov: "ASA", 2012.

Whalley I, Zhang S. Parametrie of multiple equilibria in economy directly calibrated to 5 equilibria // Economic Modelling Volume 41, August 2014, Pages 356-364.

Shumpeter I.A. History of Economic Analysis // Edited by E.B. Schumpeter - Taylor Francise- Library, 2006 $-1283 p$. 